\title{
Folga Organizacional, Rentabilidade e Características de Cooperativas de Crédito Nordestinas
}

\author{
Organizational Slack, Profitability and Characteristics of Northeastern Credit Unions
}

\author{
Ramon Rodrigues dos Santos ${ }^{1}$ \\ Aldo Leonardo Cunha Callado ${ }^{2}$ \\ Joséte Florencio dos Santos ${ }^{3}$
}

\begin{abstract}
Resumo
O presente estudo buscou analisar a relação entre os tipos de folga organizacional e a rentabilidade das cooperativas de crédito nordestinas, além de suas características, como o tamanho, a livre admissão de associados e a influência sobre os resultados negativos e sobre as cooperativas centrais. Para alcançar os objetivos da pesquisa, foram considerados os dados trimestrais de 84 cooperativas de crédito nordestinas, no período de março de 2014 a setembro de 2015 , em um total de 588 observações, através de uma modelagem de dados em painel. Os resultados evidenciaram a relação entre os tipos de folga organizacional e a rentabilidade dessas instituições, com características relacionadas ao resultado negativo e a serem cooperativas centrais, destacando que a adoção dos tipos de folga organizacional possibilita uma gestão estratégica da performance financeira e operacional das instituições. As principais contribuições deste artigo estão relacionadas ao diagnóstico do desempenho das cooperativas de crédito nordestinas, além de promover discussões sobre a influência dos tipos de folga organizacional em instituições financeiras que possuem uma metodologia contábil diferenciada.
\end{abstract}

Palavras-chave: folga organizacional. cooperativas de crédito. rentabilidade.

\begin{abstract}
The present study sought to analyze the relation between the types of organizational slack and the profitability of northeastern credit unions, in addition to their characteristics, such as size, free admission of members, and the influence on negative results and central cooperatives. In order to achieve the research objectives, quarterly data from 84 northeastern credit unions, from March 2014 to September 2015, were considered in a total of 588 observations, through panel data modeling. The results showed the relation between the types of organizational slack and the profitability of these institutions, with characteristics related to the negative result and being central cooperatives, highlighting that the adoption of the types of organizational slack enables strategic management of the financial and operational performance of the institutions. The main contributions of this article are related to the diagnosis of the performance of credit unions in the Northeast, in addition to promoting discussions about the influence of types of organizational slack in financial institutions that have a different accounting methodology.
\end{abstract}

Keywords: organizational slack. credit unions. profitability.

9 Doutorando em Administração pela Universidade Federal de Pernambuco (UFPE). Mestre em Administração pela Universidade Federal da Paraíba (UFPB).

Doutor em Agronegócios pela Universidade Federal do Rio Grande do Sul (UFRGS). Professor Associado do Departamento de Finanças e Contabilidade da Universidade Federal da Paraíba (UFPB). da Universidade Federal de Pernambuco (UFPE). 


\section{Introdução}

As cooperativas de crédito, como uma alternativa de cunho social, procuram um equilíbrio entre o seu desempenho financeiro e o social, uma vez que as sobras, isto é, a rentabilidade gerada pelos serviços e produtos financeiros, retornam aos seus cooperados, denotando a relação mútua e cíclica desse modelo organizacional. Essa dimensão influencia diretamente o crescimento dessas instituições, uma vez que, crescendo financeira e economicamente, geram condições para a expansão da sua atuação e do portfólio de produtos e serviços financeiros aos seus cooperados (FREITAS; FREITAS, 2014).

Com isso, mesmo as instituições que privilegiam associações de baixa renda devem colocar em destaque esse aspecto, salvaguardando certa taxa de crescimento por critério de folga organizacional, entendida como um potencial mecanismo de gestão para a empresa contra eventos externos e incertos, e que contribui para a tomada de decisões em relação aos riscos inerentes e à avaliação de desempenho (BOURGEOIS III; SINGH, 1983; CAMPOS; NAKAMURA, 2013), ramificada em três aspectos - que, mesmo inter-relacionados, possuem uma conceituação diferente -, quais sejam: as folgas disponível, recuperável e potencial.

Nesse aspecto, tem-se a seguinte questão de pesquisa: Qual a relação entre os tipos de folga organizacional com a rentabilidade de cooperativas de crédito nordestinas? $O$ objetivo deste trabalho é analisar a relação entre os tipos de folga organizacional e a rentabilidade das cooperativas de crédito nordestinas no período de março de 2014 a setembro de 2015. Para a análise de dados, adaptaram-se as métricas de cálculo dos tipos de folga do estudo de Beuren e Dallabona (2015) a partir do Plano Contábil das Instituições do Sistema Financeiro Nacional, o Cosif.

As cooperativas de crédito em regiões menos desenvolvidas têm a possibilidade de funcionar melhor que o tradicional sistema financeiro, devido ao mutualismo existente entre os associados e a cooperativa, a partir do capital social existente, e sua respectiva maximização, o que reduz possíveis conflitos (MCKILLOP; WILSON, 2011; BANERJEE et al., 2014). Além disso, considerando-se os fatos anteriores e a realidade dessas instituições no Brasil, soma-se o fato de que as cooperativas se caracterizam como uma sociedade de pessoas, isto é, uma instituição que relaciona sua eficiência muito mais à supressão das necessidades dos seus associados do que, necessariamente, à acumulação dos resultados (FREITAS; FREITAS, 2014).

Em relação à distribuição geográfica das cooperativas de crédito, aproximadamente 6\%, ou 290 unidades de atendimento, conforme dados do Sistema Nacional de Crédito Cooperativo (FGCOOP, 2015), estão localizadas na Região Nordeste, com predominância para os sistemas de segundo nível (os compostos pelas cooperativas centrais de crédito junto às suas filiadas). Em contraponto à tímida participação, trata-se da região que capta recursos superiores à concessão de crédito, inferindo-se a existência de disponibilidade às demandas por empréstimos e financiamentos e que possuem estados que possuem índices acima da média nacional (MEINEN; PORT, 2014).

Com a finalidade de responder ao problema desta pesquisa, investigou-se a relação entre os principais tipos de folga elencados pela literatura e as características de tamanho da cooperativa de crédito e sua classificação como uma instituição de livre admissão (que são as que permitem a associação de qualquer pessoa física ou jurídica, independente do segmento).

Nesse contexto, após esta introdução, discorre-se sobre as cooperativas de crédito, os tipos de folga organizacional e, junto aos tópicos, as pesquisas anteriores que destacam as temáticas apresentadas. Na terceira parte, sobre os procedimentos metodológicos, as variáveis da pesquisa e o modelo econométrico. Por fim, apresentamse a análise dos resultados, as considerações finais e as referências.

\section{Revisão da Literatura}

\subsection{Cooperativas de crédito nordestinas}

As organizações cooperativas têm a sua origem relacionada às necessidades de agricultores, artesãos e operários que se organizaram, como uma forma de "defesa", frente às situações de mercado. Diante disso, deuse início a pequenos grupos de trabalhadores que se uniam com a finalidade de dirimir problemas financeiros uns dos outros (ETGETO et al., 2005).

Uma cooperativa de crédito é uma instituição financeira de propriedade do associado, controlada democraticamente por seus membros e operada com o objetivo de maximizar o benefício econômico desses, fornecendo serviços financeiros a taxas competitivas e justas (WORLD COUNCIL OF CREDIT UNIONS, 2019). De forma geral, essas instituições buscam desenvolver um equilíbrio entre o seu desempenho financeiro e o social, uma vez que os lucros para essas entidades são, na verdade, excedentes ou "sobras" apuradas pelo resultado de produtos e serviços no fim de cada ciclo anual. Essa dimensão influencia diretamente o crescimento dessas instituições, que possuem características específicas relacionadas à política de intermediação financeira (RIXON; LIGHTSTONE, 2016).

De acordo com o Conselho Mundial das Cooperativas de Crédito (Woccu, na sigla em inglês), em 2017, existiam 89.026 cooperativas de crédito em 117 países, em um total de aproximados 260.164 .742 cooperados. Na América 
Latina, as denominadas credit unions existem em 17 países, com 2.987 unidades e 39.291.611 membros. Desses dados, o Brasil é responsável por 967 cooperativas (32,4\%) e 9.632 .007 cooperados (24,5\%) (WOCCU, 2019b).

A participação das cooperativas de crédito aumentou em todos os principais agregados do Sistema Financeiro Nacional (SFN), atingindo os seus máximos históricos, e, em alguns casos, acima do segmento bancário - o índice de Basileia das cooperativas de crédito, por exemplo, manteve-se em torno de $30 \%$, acima do índice do segmento bancário, que era de 17,2\% em 2017 (BANCO CENTRAL DO BRASIL, 2018). Em relação à Região Nordeste, a inserção das cooperativas de crédito se deu de forma verticalizada, concentrada, principalmente, no início dos anos 90 , pela origem das duas principais cooperativas centrais, permitindo ampliar a sua forma de atuação e a consequente captação de recursos na região, por menos significativa que seja, quando comparada à atuação em outras regiões (MEINEN; PORT, 2014).

As cooperativas, em razão de seus valores, princípios e das necessidades de seus integrantes, não escolhem apenas as melhores praças ou preferem cidadãos e empresas mais afortunados. Dito de outra forma, não deixam as pequenas comunidades e as classes de menor renda ao desamparo. Prova disso é que, em cerca de $10 \%$ dos municípios brasileiros e para inúmeros grupos de assalariados, as cooperativas são as únicas instituições financeiras a oferecer instalações, estrutura de pessoal e portfólio de operações e serviços decentes (MEINEN, 2016).

Em 2017, as cooperativas de crédito da Região Nordeste foram responsáveis por cerca de $4 \%$ dos principais agregados das cooperativas, participação essa com variações mínimas nos últimos anos. Diferentemente das outras regiões, a principal modalidade na carteira de pessoas físicas foi a de empréstimos com consignação em folha de pagamento, que respondeu por 33\% da carteira de dezembro de 2017, com destaque para o estado da Paraíba, concentrada em singulares de livre admissão e de servidores. Em complemento, a taxa de crescimento anual dos depósitos nas singulares sediadas na Região Nordeste manteve-se em torno de $20 \%$ nos últimos anos. Já as operações de crédito sofreram redução em sua taxa de crescimento durante a crise econômica mais intensa que a média do segmento, mas sem apresentar decréscimo e com significativa recuperação durante esse período (BACEN, 2018). Nesse aspecto, trata-se de uma tendência que, quando comparada às demais regiões, é tímida, mas sinaliza uma crescente implantação do cooperativismo de crédito nessa região.

\subsection{Folga organizacional em cooperativas de crédito}

A relação de agência é um contrato no qual o principal delega a outra pessoa a realização de algum serviço em seu nome, e envolve a autoridade para a tomada de decisão. Se ambas as partes na relação são maximizadoras de utilidade, existem boas razões para se acreditar que o agente não irá sempre agir buscando o melhor interesse do principal (JENSEN; MACKLING, 1976).

No caso das cooperativas de crédito, as relações de conflito de agência são específicas para esse tipo de organização, em uma perspectiva principal-principal, pois todos os cooperados são proprietários, e somente com a utilização dos serviços e da participação do cooperado é que a cooperativa se tornará mais forte e capaz de oferecer melhores serviços. Entretanto, devido a um distanciamento natural entre cooperado e gestor, é que este acaba por obter informação privilegiada em relação ao cooperado a respeito do desempenho atual e, provavelmente, futuro da empresa, causando a chamada assimetria informacional (TRINDADE; BIALOSKORSKI NETO, 2014).

Ademais, como em outras tipologias organizacionais, grupos dominantes tendem a nortear decisões e comportamentos para benefício próprio, como na atitude do agente em relação ao risco, no diferencial do capital investido, e no interesse de determinados grupos tomarem ou pouparem crédito, mantendo ou não uma folga organizacional na instituição, fazendo com que o principal esteja inerte à situação ou, até mesmo, com que aceite os interesses do agente a partir dos resultados que são apresentados, conforme destacado pelas proposições da corrente positivista da teoria (WESTRUP; CAMILO; ESTEVAM, 2017).

A folga organizacional é uma espécie de "colchão" de potenciais recursos que possibilitam uma vantagem competitiva em detrimento às demais organizações, os incorporando em momentos de expansão e minimizando-os em momentos de crise (BOURGEOIS III; SINGH, 1983). Cabe ressaltar que a folga organizacional não está relacionada só com uma folga de recursos financeiros, mas também com aspectos como quantidade de empregados em excesso, capacidade ociosa, despesas de capital, margens e receitas obtidas por clientes ou, até mesmo, inovações ligadas à fronteira tecnológica (KRESPI; STAROSKI FILHO; BEUREN, 2012). A folga organizacional divide-se em três aspectos que, mesmo relacionados, possuem funções distintas no processo de gestão: as folgas disponível, recuperável e potencial.

A folga disponível está relacionada ao excesso de liquidez, isto é, os recursos que, pertencentes à empresa, ainda não foram absorvidos. A folga recuperável, também denominada de absorvida, consiste nos recursos que, ora absorvidos pela empresa, podem ser revertidos durante períodos de adversidade, a exemplo do excesso da mão de obra. Por fim, a folga potencial denota a capacidade da empresa em obter recursos externos, como um financiamento por dívida (BOURGEOIS III; SINGH, 1983).

Com isso, a folga só aparece quando a empresa não está em equilíbrio, podendo estar relacionada a recursos ociosos e a comportamentos gerenciais prejudiciais ao desempenho, devendo ser minimizada por uma questão de eficiência, uma vez que pode incentivar ações gerenciais que prejudiquem o desempenho da organização. Nesse contexto, essa abordagem é oposta à teoria organizacional em sua perspectiva contingencial, que, de forma geral, afirma 
que as empresas possuem como objetivo final a sobrevivência. A disponibilidade de folga, pela teoria contingencial, forneceria os meios para o alcance da flexibilidade, permitindo que as instituições desenvolvam, imediatamente, opções de estratégia para adotar de forma ofensiva, melhorando, consequentemente, o seu desempenho de longo prazo (SHARFMAN et al., 1998).

No Brasil, pesquisas recentes envolvendo folga organizacional são escassas. Estas têm associado esse aspecto: ao desempenho das empresas (KRESPI; STAROSKI FILHO; BEUREN, 2012); à folga organizacional, inovação e desempenho (MURRO et al., 2014); à folga e inovação (BECK; BEUREN, 2014); e à folga organizacional e níveis diferenciados de governança corporativa (DALLABONA; DIEL; LAVARDA, 2014). Assim, em razão das teorias apresentadas - isto é, entre uma perspectiva que, ao mesmo tempo, pode promover um incentivo a oportunidades e ao enfrentamento de ameaças, e também pode ser considerada uma forma de desperdício de despesa, que afeta de forma negativa o resultado das instituições -, o gestor sofre pressões para empreender decisões favoráveis e parcimoniosas aos interesses do tomador e do poupador.

Esse trade-off poderia induzir uma maior rentabilidade nas cooperativas de crédito brasileiras a partir do nível da folga organizacional, uma vez que, enquanto o tomador de recursos, a fim de realizar seus projetos, tem a pretensão de pagar o menor custo possível, o poupador, ao alocar recursos excedentes, pretende que sejam remunerados por taxas dentro de sua expectativa (WESTRUP; CAMILO; ESTEVAM, 2017).

\subsection{Estudos correlatos}

Não é possível identificar na literatura trabalhos que explorem a folga organizacional em cooperativas de crédito, entretanto é possível analisar artigos que relacionem o desempenho dessas instituições (em destaque, sua rentabilidade) e a utilização de instituições e períodos diferentes. Nesse contexto, o presente tópico apresenta os estudos mais recentes.

Carvalho et al. (2015) tiveram por objetivo investigar os fatores que afetaram a saída do mercado de 1.929 cooperativas de crédito singulares brasileiras de 1995 a 2009, buscando, entre outros aspectos, analisar se a rentabilidade é um fator significativo para a sobrevivência da cooperativa de crédito. Com base em modelos de sobrevivência e no modelo de riscos competitivos, os resultados demonstram que não há evidências estatísticas que garantam uma correlação entre rentabilidade e sobrevivência da cooperativa de crédito. Em conclusão, os resultados confirmam a ideia inicial de que a dualidade inerente às cooperativas de crédito - princípios cooperativos versus eficiência econômica - poderia influenciar a estabilidade, a sobrevivência e a longevidade dessas instituições.

O trabalho de Silva, Padilha e Silva (2015) buscou analisar a performance econômicofinanceira das 25 maiores cooperativas de crédito brasileiras, no período entre 2008 a 2012, aplicando o método Topsis e regressão logística. Os resultados mostraram que os indicadores relação entre despesas de obrigações por empréstimos e repasses com as obrigações por empréstimos e repasses médios (R4), relação entre despesas operacionais com ativo total médio (R6) e relação entre o resultado da intermediação financeira pela receita operacional (R9), do grupo taxa e retornos de custos, foram os principais indicadores com impacto no ranking formado. Dessa forma, a performance econômico-financeira das cooperativas analisadas relacionou-se com a eficiência da gestão em termos de controle de custos operacionais.

A sustentabilidade de longo prazo de cooperativas e bancos demanda a identificação e a comparação das variáveis que influenciam sua rentabilidade. Nesse aspecto, Bittencourt et al. (2017) realizaram a análise de um painel de instituições bancárias e cooperativas de crédito com características similares, compreendendo o período de 2009 a 2013. Os resultados indicaram que o retorno sobre o ativo dessas instituições mostrou-se afetado por: empréstimos, eficiência (mensurada por meio de análise envoltória de dados), despesas totais, depósitos totais, outras receitas e taxa Selic. Já o retorno sobre o patrimônio líquido mostrouse influenciado por: depósito total, empréstimo, taxa Selic, PIB, inflação, outras receitas e despesas totais. Na amostra estudada, os resultados indicaram que, quando considerado o ROE como medida de desempenho, não há diferença estatística se a instituição financeira for classificada como banco múltiplo ou como cooperativa de crédito.

Por fim, Kich e Campos (2018) tiveram como objetivo analisar e comparar os índices de desempenho econômicofinanceiro das cooperativas de crédito Sicoob e Unicred no período entre 2013 a 2015 . Em relação aos procedimentos metodológicos, a pesquisa foi classificada como básica, com uma abordagem qualitativa e quantitativa, com objetivos descritivos e procedimentos técnicos, documental e bibliográfico. No período pesquisado, os resultados demonstram que a cooperativa que teve melhores resultados nos índices de liquidez, solvência e capital de risco foi a Unicred, porém, nos índices de rentabilidade, spread e eficiência, foi o Sicoob.

Considerando-se os trabalhos supracitados e as pesquisas realizadas em períodos anteriores, ratifica-se a importância, de forma pontual, de analisar a relação dos tipos de folga organizacional com a rentabilidade das cooperativas de crédito nordestinas, enfatizando que pesquisas brasileiras que abordem esse objeto de pesquisa são necessárias para que a temática possa se tornar desenvolvida, organizada e estruturada no país. 


\section{Procedimentos Metodológicos}

A amostra preliminar definida para o desenvolvimento desta pesquisa foi composta por cooperativas de crédito nordestinas, singulares e centrais, filiadas ou não aos sistemas cooperativos existentes, sob a supervisão do Banco Central do Brasil (Bacen), que estivessem em funcionamento no país e que tivessem enviado as informações financeiras à supervisora no respectivo período. O tamanho da amostra da pesquisa, durante o período analisado, variou entre 93 a 102 cooperativas (em março de 2014), contando com um total de 675 observações, com dados em periodicidade trimestral, entre março de 2014 e setembro de 2015 (sete períodos).

Os dados utilizados no presente estudo foram obtidos no IF.data (BACEN, 2015b), que já desconsidera as cooperativas em processo de incorporação cujos dados foram consolidados em suas respectivas Assembleias Extraordinárias, de acordo com a Circular . $^{\circ} 3.017$ do Bacen e o período escolhido por conveniência, conforme a disponibilização para o estudo (CORRAR; THEÓPHILO, 2010).

Em relação à operacionalização deste artigo, de forma geral, os índices de rentabilidade relacionam os resultados obtidos pela instituição a partir de valores que expressam a sua dimensão relativa. Portanto, do valor de vendas, ativo total, patrimônio líquido ou ativo operacional da empresa, tornando mais visível o desempenho da entidade, independente do seu porte (MARTINS; MIRANDA; DINIZ, 2014).

A literatura que versa sobre folga organizacional e rentabilidade utiliza, em geral: o retorno sobre ativo (ROA) como variável de desempenho (LIMA et al., 2015); ROA em conjunto com a rentabilidade do patrimônio líquido (RPL ou ROE) (DALLABONA et al., 2013; DIEL et al., 2015; BEUREN; STAROSKY FILHO; KRESPI, 2014); ou as três medidas de rentabilidade (ROA, RPL e ROI) para identificar a relação supracitada (BEUREN; DALLABONA, 2015).

A análise da ROA, isto é, a comparação do ativo com a rentabilidade reproduzida por este, não é consistente, uma vez que esse índice mistura dois conceitos importantes que deveriam ser tratados de forma separada: o lucro derivado das atividades operacionais ativas da empresa e o gerado pelo efeito das despesas financeiras provenientes do passivo de financiamento (MARTINS; DINIZ; MIRANDA, 2012).

Em relação ao ROI, é um dos indicadores mais utilizados pelas empresas e pelos investidores (MARTINS; MIRANDA; DINIZ, 2014), uma vez que a rentabilidade do negócio depende do capital investido na atividade. Entretanto esse conceito, em instituições financeiras e, especificamente, em cooperativas de crédito, difere das demais empresas, devido à metodologia contábil utilizada pelo Plano Cosif. De forma geral, de acordo com a Resolução n. ${ }^{\circ} 4.434$, em seu artigo 54, os investimentos realizados pelas cooperativas de crédito estão intrinsecamente relacionados às cotas de participação nas suas respectivas cooperativas centrais, instituições financeiras controladas por outra cooperativa de crédito (singular, central, confederação ou que atue majoritariamente na prestação de serviços a instituições do setor cooperativo de crédito) (BACEN, 2015). Com isso, propõe-se, neste trabalho, apenas a utilização do RPL, uma vez que o seu resultado, de forma geral, pode sensibilizar os efeitos alcançados pela gestão da empresa ao administrar os seus próprios recursos e de terceiros em benefício dos acionistas (MARTINS; MIRANDA; DINIZ, 2014). No caso desta pesquisa, aos respectivos cooperados. Assim sendo, a partir das questões supracitadas, foi proposto o seguinte modelo econométrico:

$$
R P L_{i t}=\alpha_{i t}+\beta_{1} F D_{i t}+\beta_{2} F R_{i t}+\beta_{3} F P_{i t}+\beta_{4} T A M_{i t}+\beta_{5} L I V_{i t}+\beta_{6} P E R D_{i t}+\beta_{7} C E N T_{i}+\varepsilon_{i t}
$$

Em que: $R P L_{\mathrm{it}}$ : rentabilidade do patrimônio líquido da cooperativa $i$ no período $t$, calculado pela relação entre o lucro líquido e o patrimônio líquido ajustado; $F D_{\mathrm{it}}$ : folga disponível da cooperativa i no período $\mathrm{t} ; F R_{\mathrm{it}}$ : folga recuperável da cooperativa $i$ no período $t ; F P_{\mathrm{it}}$ : folga potencial da cooperativa $i$ no período $t$; $T A M_{\mathrm{it}}$ : tamanho da empresa, representado pelo logaritmo neperiano do ativo total da cooperativa $i$ no período $t ; L I V_{\text {it }}$ : variável dummy para as cooperativas de livre admissão no período t, assumindo o valor 1 caso seja e 0 caso crédito mútuo ou rural; $P E R D_{\text {it: }}$ variável dummy para as cooperativas com prejuízo no período $t$, assumindo o valor 1 se apresentou e 0 caso tenha apresentado sobras líquidas; e $C E N T_{\mathrm{i}}$ : variável dummy para as cooperativas centrais, assumindo 1 caso seja e 0 caso cooperativa singular.

Os tipos de folga organizacional foram adaptados à metodologia contábil pelo Plano Cosif (BACEN, 1987), devido à indisponibilidade de estudos sobre folga organizacional em cooperativas de crédito. Com isso, os dados necessários para o cálculo dos indicadores estão apresentados no Quadro 1, com o sinal esperado, baseado na literatura sobre a temática.

Quadro 1 - Variáveis explicativas e sinal esperado

\begin{tabular}{|c|c|c|}
\hline Variável & Métricas & Sinal esperado \\
\hline FD & (LL - Dividendos/Vendas + (Disponível - PC/Vendas) - (Dividendos/ PL) & + \\
FR & (Despesas / Vendas) + (Contas a receber / Vendas) + (Estoques /Vendas) & + \\
FP & Patrimônio líquido / Capital de terceiros & - \\
\hline
\end{tabular}

Legenda: FD: folga disponível; FR: folga recuperável; FP: folga potencial; LL: lucro líquido; PC: passivo circulante; PL: patrimônio líquido. Fonte: Adaptado de Beuren e Dallabona (2015), baseado no Cosif (BACEN, 1987). 
Cabe ressaltar que, somado aos dividendos (que, no caso, refletem-se no valor das sobras distribuídas aos cooperados), acrescentam-se os juros sobre o capital próprio (JSCP) à cota-parte de capital, conforme a Lei n. ${ }^{\circ} 5.764$ (BRASIL, 1971). Em sequência, além das variáveis independentes relacionadas aos tipos de folga organizacional, o presente trabalho propõe estabelecer relações com determinados aspectos das cooperativas de crédito estudadas, caracterizadas como variáveis de controle, ora destacadas no Quadro 2.

Quadro 2 - Variáveis de controle e sinal esperado

\begin{tabular}{|c|c|c|}
\hline Variável & Métricas & Sinal Esperado \\
\hline TAM & log neperiano (AT) & + \\
LIV & 1 se livre admissão e 0 caso contrário & - \\
PERD & 1 se há prejuízo e 0 caso contrário & + \\
CENT & 1 se cooperativa central e 0 caso contrário & + \\
\hline
\end{tabular}

Fonte: Elaboração própria.

Conforme consta no Quadro 2, a primeira variável está relacionada ao tamanho da cooperativa em termos do logaritmo neperiano do seu ativo total, com a finalidade de analisar se a maior rentabilidade das cooperativas de crédito nordestinas pode estar intrinsecamente associada ao seu porte. Para futuros trabalhos, essa variável poderá ser substituída pela receita com intermediação financeira ou pela quantidade de funcionários, como no estudo de Dallabona et al. (2013).

A segunda variável considera as categorias instituídas pelo Bacen para as cooperativas de crédito - livre admissão, mútuo e rural - e está relacionada às cooperativas que admitem associados com qualquer profissão. Dessa forma, a estimação com a variável binária captará o efeito médio da livre admissão de associados na relação entre os tipos de folga organizacional e a rentabilidade do patrimônio líquido. Das 84 cooperativas de crédito nordestinas analisadas neste trabalho, 18 (ou aproximados $21 \%$ da amostra) são de livre admissão.

A terceira variável dummy propõe analisar se as cooperativas que tiveram resultado líquido negativo tiveram, em média, uma maior folga organizacional a fim de proteger a sua situação financeira. Parte-se do pressuposto de que, quanto maior o prejuízo, menor a folga de recursos das cooperativas, a fim de manter a sua situação financeira estabilizada, em detrimento ao seu desempenho econômico.

Por fim, a última variável de controle, também caracterizada por uma dummy, está relacionada a se a questão de uma cooperativa ser uma central contribui para uma maior folga, uma vez que, conforme a Resolução n. ${ }^{\circ} 4.434$ (BACEN, 2015), uma de suas diretrizes é a centralização financeira das disponibilidades líquidas das cooperativas filiadas e, em algumas, o pagamento de despesas comuns entre as cooperativas, sendo posteriormente rateadas, por exemplo, como tributos.

\section{Apresentação e Discussão dos Resultados}

\subsection{Análise exploratória dos dados}

De forma preliminar, antes da aplicação do modelo proposto, a partir da metodologia de dados em painel, realizou-se uma análise descritiva da variável dependente (a RPL) com seus estimadores. De acordo com os resultados apresentados na Tabela 1, a folga disponível (que estabelece uma relação entre o ativo circulante e o passivo exigível) foi a que teve uma maior discrepância entre as cooperativas de crédito nordestinas, enquanto a folga recuperável foi a que apresentou uma maior aproximação com a média.

Tabela 1 - Estatísticas descritivas

\begin{tabular}{cccccc}
\hline Variável & Média & Mediana & Mínimo & Máximo & Desv. padrão \\
\hline RPL & 0,0214146 & 0,0404596 & $-1,68447$ & 0,969697 & 0,151943 \\
FD & 2,22571 & 1,37018 & 1,01326 & 33,9841 & 3,67580 \\
FR & 0,607845 & 0,579509 & 0,000000 & 3,43956 & 0,346027 \\
FP & 3,57049 & 3,13677 & 0,0270270 & 26,1408 & 2,37191 \\
\hline
\end{tabular}

Fonte: Resultados da pesquisa.

Com isso, a partir da amostra estudada, entende-se que as cooperativas possuem diferentes estratégias, relacionadas à alocação das suas disponibilidades em proporção ao seu endividamento, e que os dispêndios com 
pessoal e administração tendem a se comportar de maneira homogênea entre as instituições, com a recuperação dessas despesas que, operacionalmente, são responsáveis por suas receitas.

Em relação à folga potencial, isto é, à capacidade da empresa em gerar aumento do seu capital (DIEL et al., 2015), foi percebida uma diferença significativa entre a capacidade de determinadas cooperativas de crédito gerarem riqueza em relação às outras, considerado o intervalo de confiança a $5 \%(1,10)$ e a $95 \%(7,27)$ comparado ao máximo $(26,14)$. Por fim, a rentabilidade do patrimônio líquido teve uma variabilidade pequena, com um desvio-padrão de $15 \%$, também caracterizado pela proximidade da mediana das observações em relação à média.

Posterior à análise descritiva, realizou-se o teste de fator de inflação da variância, o FIV, com a finalidade de verificar a possível existência de multicolinearidade entre os estimadores, partindo do pressuposto de que valores mais próximos a 1 destacam que o conjunto de variáveis não é correlacionado, e que acima de 10,0 (em critérios mais conservadores, acima de 5,0) poderiam indicar um problema de multicolinearidade e consequente quebra de pressupostos econométricos, o que, de acordo com os resultados, não ocorreu, validando a estimação do modelo proposto. Além disso, considerando o teorema do limite central e a utilização de 588 observações, o pressuposto da normalidade pôde ser relaxado (GUJARATI, 2012).

Tabela 2 - Teste FIV

\begin{tabular}{ccccccc}
\hline FD & FR & FP & LogAT & LIV & PERD & CENT \\
\hline 1,140 & 1,307 & 1,411 & 1,888 & 1,282 & 1,531 & 1,370 \\
\hline
\end{tabular}

Fonte: Resultados da pesquisa.

De acordo com os resultados apresentados na Tabela 2, apesar de nem todas as variáveis terem apresentados valores próximos de 1, nenhuma apresentou valor superior a 2. Com isso, buscou-se, através de uma matriz, analisar o comportamento entre as principais variáveis deste estudo e se apresentariam uma alta correlação, conforme consta na Tabela 3.

Tabela 3 - Matriz de correlação

\begin{tabular}{|c|c|c|c|c|c|c|c|c|}
\hline RPL & FD & FR & FP & LogAT & LIV & PERD & CENT & \\
\hline \multirow[t]{8}{*}{1} & $-0,01$ & $-0,25$ & $-0,45$ & 0,28 & 0,16 & $-0,55$ & $-0,01$ & RPL \\
\hline & 1 & 0,10 & $-0,29$ & $-0,19$ & $-0,12$ & $-0,05$ & $-0,07$ & FD \\
\hline & & 1 & $-0,02$ & $-0,37$ & $-0,19$ & 0,33 & 0,15 & $\mathrm{FR}$ \\
\hline & & & 1 & 0,15 & $-0,05$ & 0,22 & 0,38 & $\mathrm{FP}$ \\
\hline & & & & 1 & 0,41 & $-0,48$ & 0,23 & $\log A T$ \\
\hline & & & & & 1 & $-0,23$ & $-0,12$ & LIV \\
\hline & & & & & & 1 & $-0,02$ & PERD \\
\hline & & & & & & & 1 & CENT \\
\hline
\end{tabular}

Fonte: Resultados da pesquisa.

Os resultados destacaram que nenhuma das relações entre as variáveis obteve um coeficiente de correlação forte. O maior coeficiente de correlação, a partir da amostra estudada, ocorreu entre a folga potencial e a rentabilidade do patrimônio líquido $(-0,45)$. Esse fato já era esperado, uma vez que, quanto menor o nível de endividamento das cooperativas de crédito nordestinas em relação ao capital próprio, maior será a sua rentabilidade e vice-versa (MEINEN; PORT, 2014). Além disso, a relação entre o tamanho da empresa e o prejuízo das cooperativas (correlação de -0,48) destacou que, quanto menor o porte da cooperativa, maior o prejuízo.

\subsection{Análises do painel e discussão dos resultados}

De acordo com a Tabela 4, em torno de 46\% da variação na rentabilidade do patrimônio líquido das cooperativas de crédito estudadas pode ser explicada por critérios de folga organizacional. Conforme Fávero et al. (2009), é comum que a modelagem dos dados por painel destaque valores de $\mathrm{R}^{2}$ medianos, entretanto satisfatórios para explicar $\mathrm{o}$ comportamento das variáveis. 
Tabela 4 - Resultados da equação (1)

\begin{tabular}{|c|c|c|c|c|c|}
\hline \multicolumn{6}{|c|}{ Painel A } \\
\hline Variáveis & Coeficiente & Erro padrão & Estatística t & p-valor & \\
\hline Const & 0,156484 & 0,0337055 & 4,6427 & $<0,0001$ & *** \\
\hline FD & $-0,00506926$ & 0,00133677 & $-3,7922$ & 0,0002 & $* * *$ \\
\hline FR & $-0,0535423$ & 0,0152063 & $-3,5211$ & 0,0005 & $* * *$ \\
\hline FP & $-0,029969$ & 0,00230501 & $-13,0017$ & $<0,0001$ & $* * *$ \\
\hline LogAT & 0,00383783 & 0,00308706 & 1,2432 & 0,2143 & \\
\hline LIV & 0,00328328 & 0,0126906 & 0,2587 & 0,7959 & \\
\hline PERD & $-0,154065$ & 0,0149678 & $-10,2931$ & $<0,0001$ & $* * *$ \\
\hline CENT & 0,115839 & 0,0252716 & 4,5838 & $<0,0001$ & $* * *$ \\
\hline \multicolumn{6}{|c|}{ Painel B } \\
\hline Média var. dependente & 0,021415 & \multicolumn{2}{|c|}{ D.P. var. dependente } & \multicolumn{2}{|c|}{0,151943} \\
\hline Soma resíd. quadrados & 7,211210 & \multicolumn{2}{|c|}{ E.P. da regressão } & \multicolumn{2}{|c|}{0,111504} \\
\hline$F(5,580)$ & 72,85434 & \multicolumn{2}{|c|}{ P-valor(F) } & \multicolumn{2}{|c|}{$2,31 \mathrm{e}-75$} \\
\hline
\end{tabular}

Legenda: Significância: ${ }^{* * *}: 1 \%,{ }^{* *}: 5 \%$ *: 10\%. Fonte: Resultados da pesquisa.

De forma geral, as variáveis FD e FR também mostraram significância a 1\%, destacando, através do sinal negativo, que, quanto menor a folga recuperável, maior a rentabilidade das cooperativas de crédito investigadas e vice-versa. Para Camargos e Barbosa (2010), a eficiência operacional está relacionada ao aumento da margem operacional da instituição e, por consequência, ao seu lucro, fazendo crescer a rentabilidade dos seus ativos e uma execução eficiente a partir da integração entre as empresas, possibilitando até a redução dos seus gastos em seus setores administrativos. Com isso, a recuperação das despesas gerais, mensuradas pelas despesas administrativas, somada com as despesas de pessoal, através das receitas (principalmente as de intermediação financeira, o core business da cooperativa de crédito), pode refletir essa eficiência.

Já a relação com a folga potencial apresentou uma relação negativa, mostrando que, quanto menor, maior o desempenho econômico. A evolução da ideia central de estratégia está relacionada à prática dos processos dinâmicos que, continuamente, revisa as suas missões, estratégias e operações relacionadas à necessidade dos clientes e à força do mercado em diversas áreas, como marketing ou gestão estratégica (WHITTINGTON; CAILLUET; YAKIS-DOUGLAS, 2011).

Enquanto isso, a variável de controle e o tamanho, além da dummy relacionada ao segmento de livre admissão, não apresentaram significâncias estatísticas positivas. Com isso, de forma geral, o porte e a característica da instituição oferecer a livre admissão de associados não seria suficiente para impactar em uma maior rentabilidade. Quando realizada uma regressão, desconsiderando-se as variáveis TAM e LIV, isto é,

$$
R P L_{i t}=\alpha_{i t}+\beta_{1} F D_{i t}+\beta_{2} F R_{i t}+\beta_{3} F P_{i t}+\beta_{4} P E R D_{i t}+\beta_{5} C E N T_{i}+\varepsilon_{i t}
$$

conforme resultados apresentados na Tabela 6 , percebeu-se que o poder explicativo do modelo $\left(R^{2}\right.$ ajustado $)$ ficou praticamente inalterado, e apresentou os mesmos sinais da equação anterior.

Tabela 5 - Resultados da equação (2)

\begin{tabular}{|c|c|c|c|c|c|}
\hline \multicolumn{6}{|c|}{ Painel A } \\
\hline Variáveis & Coeficiente & Erro padrão & Estatística $t$ & $\mathrm{p}$-valor & \\
\hline const & 0,198001 & 0,0131873 & 15,0145 & $<0,0001$ & *** \\
\hline FD & $-0,00541513$ & 0,00131481 & $-4,1186$ & $<0,0001$ & *** \\
\hline FR & $-0,0594964$ & 0,0146201 & $-4,0695$ & $<0,0001$ & *** \\
\hline FP & $-0,0295604$ & 0,0022818 & $-12,9549$ & $<0,0001$ & *** \\
\hline PERD & $-0,163584$ & 0,0134546 & $-12,1582$ & $<0,0001$ & $* * *$ \\
\hline CENT & 0,122455 & 0,0241537 & 5,0698 & $<0,0001$ & *** \\
\hline \multicolumn{6}{|c|}{ Painel B } \\
\hline Média var. dependente & 0,021415 & \multicolumn{2}{|c|}{ D.P. var. dependente } & \multicolumn{2}{|c|}{0,151943} \\
\hline $\begin{array}{l}\text { Soma resíd. } \\
\text { quadrados }\end{array}$ & 7,237940 & \multicolumn{2}{|c|}{ E.P. da regressão } & \multicolumn{2}{|c|}{0,111518} \\
\hline R-quadrado & 0,465908 & \multicolumn{2}{|c|}{ R-quadrado ajustado } & \multicolumn{2}{|c|}{0,461320} \\
\hline$F(5,580)$ & 101,5400 & \multicolumn{2}{|c|}{ P-valor $(F)$} & \multicolumn{2}{|c|}{$6,55 \mathrm{e}-77$} \\
\hline
\end{tabular}

Legenda: Significância: ***: $1 \%,{ }^{* *}: 5 \%$ *: $10 \%$. Fonte: Resultados da pesquisa. 
De forma geral, o desempenho organizacional e sua consequente rentabilidade é um conjunto de fatores financeiros, operacionais e da sua relação com os stakeholders, e se torna paradoxal uma vez que os recursos internos e externos da instituição, muitas vezes, não convergem, devido ao mainstream da organização ou a outros aspectos, além do econômicofinanceiro (MOON, 2013).

Assim como as demais instituições financeiras, as cooperativas de crédito também estão inerentes a diversos riscos, como o de liquidez, operacional e crédito, relacionado à incerteza do cooperado não cumprir o pagamento de sua dívida (FREITAS; FREITAS, 2014). Nesse sentido, os critérios de folga organizacional se propõem a estar inseridos na dimensão financeira dessas instituições, a fim de que assegurem, em essência, as taxas de juros e os custos de serviços mais baixos, quando comparados com as demais instituições bancarias, assim como suas sobras (o lucro líquido), e, por consequência, a rentabilidade para os seus associados.

Nesse contexto, observou-se, dentro do período analisado nesta pesquisa, que as cooperativas de crédito, possivelmente, optam por menores folgas para obterem uma maior rentabilidade sobre o seu patrimônio líquido nos três tipos de folga organizacional (disponível, recuperável ou potencial). Somado a esses achados, cabe destacar a influência que ser uma cooperativa de crédito central pode ter em relação às folgas, uma vez que uma das suas diretrizes é a centralização financeira das disponibilidades líquidas das cooperativas filiadas.

\section{Considerações Finais}

O desempenho financeiro de uma instituição está relacionado à capacidade desta em gerar rentabilidade, que, refletida em seus indicadores, tem a possibilidade de atrair mais investimentos além dos que já se encontram na empresa e também investidores externos. Já o desempenho não financeiro (ou operacional) está relacionado à eficiência de uma empresa em seus processos e à crescente melhoria da sua produtividade, sensibilizada através de índices que destaquem a exemplo da capacidade de recuperar as suas despesas gerais em relação às receitas originadas pela entidade.

Nesse aspecto, questões relacionadas aos tipos de folga organizacional (disponível ou potencial, relacionadas ao desempenho financeiro, e recuperável, relacionada ao desempenho operacional) e o impacto originado no desempenho da organização são analisados a fim de verificar de que forma e se os gestores estão preocupados, ou se até mesmo são influentes no gerenciamento do seu patrimônio, uma vez que a adoção do tipo de folga organizacional possibilita uma gestão estratégica da performance financeira e operacional das instituições e, especificamente, neste trabalho, das cooperativas de crédito, completando o planejamento estratégico dessas organizações.

Com isso, o presente estudo objetivou analisar a relação entre os tipos de folga organizacional presentes na literatura e a rentabilidade de 84 cooperativas de crédito nordestinas, no período de março de 2014 a setembro de 2015, e características relacionadas ao porte dessas instituições, como permitirem a livre admissão de associados, a influência dos prejuízos na variável dependente e as cooperativas centrais da região.

Os resultados apresentados suportam a tese de que, quanto menores as folgas da cooperativa de crédito, maior a sua rentabilidade sobre o patrimônio líquido. Essa relação foi de encontro a dois dos três sinais esperados. Com isso, os gestores optariam pela maximização do capital integralizado pelos associados, através dos serviços e produtos financeiros, obtendo uma maior rentabilidade do patrimônio da entidade e, por consequência, dos seus cooperados. Visto tratar-se de uma instituição específica e não relacionada ao mercado aberto, tais questões são novas, e deverão ser ratificadas em estudos posteriores.

Como limitações dessa pesquisa, incluem-se: as métricas de folga organizacional, haja vista a existência de outras, mas que, ainda assim, não foram adaptadas às instituições financeiras, que possuem sua metodologia contábil atrelada ao Plano Cosif. Para pesquisas futuras, é pertinente o aperfeiçoamento dessas métricas através da utilização de outros indicadores financeiros, econômicos ou macroeconômicos, como variáveis explicativas ou de controle, a fim de estabelecer relações com os tipos de folga organizacional e aspectos intrínsecos às cooperativas de crédito.

\section{Referências}

BANCO CENTRAL DO BRASIL. Panorama do Sistema Nacional de Crédito Cooperativo: Data-base: dezembro/2016. [Brasília]: Banco Central do Brasil, [2018]. Link. Acesso em: 25 jul. 2019.

BANCO CENTRAL DO BRASIL. Resolução $n^{\circ}$ 4.434, de 5 de agosto de 2015. Dispõe sobre a constituição, a autorização para funcionamento, o funcionamento, as alterações estatutárias e o cancelamento de autorização para funcionamento das cooperativas de crédito e dá outras providências. Brasília: Banco Central do Brasil, 2015a. Link. Acesso em 25 jul. 2019.

BANERJEE, A. V. Do firms want to borrow more? Testing credit constrains using a directed lending program. The Review of Economic Studies, London, v. 81, n. 2, p. 572-607, 2014. 
BECK, F.; BEUREN, I. M. Interfaces da Folga Organizacional com Inovação. In: CONGRESSO DA ASSOCIAÇÃO NACIONAL DE PROGRAMAS DE PÓS-GRADUAÇÃO EM CIÊNCIAS CONTÁBEIS, 8, 2014, Rio de Janeiro. Anais[...]. Rio de Janeiro: ANPCONT, 2014. Link. Acesso em: 25 jul. 2019.

BEUREN, I. M.; DALLABONA, L. F. Relação da folga organizacional com medidas de desempenho de empresas brasileiras. Revista Pretexto, Belo Horizonte, v. 16, n. 2, p. 31-49, abr./jun. 2015. Link. Acesso em: 25 jul. 2019.

BEUREN, I. M ; STAROSKY FILHO, L.; KRESPI, N. T. Folga organizacional versus desempenho financeiro: um estudo nas empresas da BM\&FBovespa. Contaduría y Administración, Cidade do México, v. 59, n.2, p. 145-177, abr./jun. 2014. Link. Acesso em: 25 jul. 2019.

BITTENCOURT, W. R.; BRESSAN, V. G. F.; GOULART, C. P.; BRESSAN, A. A.; COSTA, D. R. de; LAMOUNIER, W. M. Rentabilidade em bancos múltiplos e cooperativas de crédito brasileiros. Revista de Administração Contemporânea, Rio de Janeiro, v. 21, Edição Especial FCG, p. 22-40, 2017. Link. Acesso em: 25 jul. 2019.

BOURGEOIS III, L. J.; SINGH, J. V. Organizational slack and political behavior among top management teams. Academy of Management Proceedings, Briarcliff Manor, p. 43-47, 1983. Link. Acesso em: 25 jul. 2019.

BRASIL. Lei n. ${ }^{\circ} 5.764$, de 16 de dezembro de 1971. Define a Política Nacional de Cooperativismo, institui o regime jurídico das sociedades cooperativas, e dá outras providências. Diário Oficial da União: Brasília, DF, 16 dez. 1971. Link. Acesso em: 25 jul. 2019.

CAMARGOS, M. A. de; BARBOSA, F. V. Fusões, aquisições e takeovers: um levantamento teórico dos motivos, hipóteses testáveis e evidências empíricas. REGE Revista de Gestão, v. 10, n. 2, 2010. Link. Acesso em: 25 jul. 2019.

CAMPOS, A. L. S.; NAKAMURA, W. T. Folga financeira avaliada como endividamento relativo e estrutura de capital. Revista de Finanças Aplicadas. São Paulo, v. 1, p. 1-19, 2013. Link. Acesso em: 25 jul. 2019.

CARVALHO, F. L. de; DIAZ, M. D. M.; BIALOSKORSKI NETO, S.; KALATZIS, A. E. G. Saída e Insucesso das Cooperativas de Crédito no Brasil: Uma Análise do Risco. Revista Contabilidade \& Finanças - USP, São Paulo, v. 26, n. 67, p. 70-84, jan./abr. 2015. Link. Acesso em: 25 jul. 2019.

CORRAR, L. J.; THEÓPHILO, C. R (org.). Pesquisa Operacional para Decisão em Contabilidade e Administração: contabilometria. 2. ed. São Paulo: Atlas, 2010.

DALLABONA, L. F.; MACOHON, E. R.; ZITTEI, M.; LAVARDA, C. E. F Antecedentes e Efeitos da folga organizacional em empresas listadas na BM\&FBovespa: análise sob as perspectivas contingencial e agência. In: ENCONTRO DA ASSOCIAÇÃO NACIONAL DOS PROGRAMAS DE PÓS-GRADUAÇÃO EM ADMINISTRAÇÃO, 37, 2013, Rio de Janeiro. Anais [...]. Rio de Janeiro: EnANPAD, 2013. Link. Acesso em: 25 jul. 2019.

DALLABONA, L. F.; DIEL, F. J.; LAVARDA, C. E. F. Variabilidade de folga organizacional de empresas listadas nos níveis diferenciados de governança corporativa da BM\&FBovespa. Registro Contábil, Maceió, v. 5, n. 2, p. 67-86, mai./ago. 2014. Link. Acesso em: 25 jul. 2019.

DIEL, F. J.; DALLACORT, A. C.; DIEL, E. H.; SILVA JUNIOR, J. C. A. da S.; DEDONATTO, O. Relação entre folga organizacional e desempenho econômico-financeiro das empresas brasileiras do setor de bens industriais listadas na BM\&FBovespa. In: SEMINÁRIOS EM ADMINISTRAÇÃO, 18, 2015, São Paulo. Anais[...]. São Paulo: FEA-USP, 2015. Link. Acesso em: 25 jul. 2019.

ETGETO, A. A.; SILVA, C. G. B.; VICENTE, F. C.; GIROTTO, M.; MIRANDA, I. Os princípios do cooperativismo e as cooperativas de crédito no Brasil. Revista de Ciências Empresariais, Umuarama v. 2, n. 1, p. 7-19, 2005.

FUNDO GARANTIDOR DO COOPERATIVISMO DE CRÉDITO. Relatório do Sistema Nacional de Crédito Cooperativo - SNCC. 2015. Link. Acesso em 11 dez. 2017.

FREITAS, A. F. de; FREITAS, A. F. de. O cooperativismo de crédito no Brasil e a emergência de uma vertente solidária. Revista Brasileira de Gestão e Desenvolvimento Regional, Taubaté, v. 10, n. 2, p. 46-74, 2014. Link. Acesso em: 25 jul. 2019. 
JENSEN, M. C.; MECKLING, W. H. Theory of the firm: managerial behavior, agency costs and ownership structure. Journal of Financial Economics, Rochester, v. 3, n. 4, p. 305-360, 1976. Link. Acesso em: 25 jul. 2019.

JONES, P. Growing Credit Unions in the West Midlands - the case for restructuring. Journal of Cooperative Studies, [s.I.], v.37, n.1, p. 5-21, 2004.

$\mathrm{KICH}$, M. C.; CAMPOS, C. G. Desempenho das Cooperativas de Crédito SICOOB e UNICRED: Um estudo dos índices econômico-financeiro entre o período de 2013 a 2015. Revista Borges, Florianópolis, v. 8, n. 1, p. 25-49, jul. 2018. Link. Acesso em: 25 jul. 2019.

KRESPI, N. T., STAROSKI FILHO, L.; BEUREN, I. M. Folga organizacional versus desempenho financeiro: Um estudo nas empresas da BM\&FBovespa. In: CONGRESSO BRASILEIRO DE CUSTOS, 19, 2012, Bento Gonçalves. Anais[...]. São Leopoldo: Associação Brasileira de Custos, 2012. Link. Acesso em: 25 jul. 2019.

LIMA, A. C. M.; ROCHA, J. S. da; DIAS FILHO, J. M.; GONÇALVES, D. E. S. Folga organizacional e desempenho financeiro sob a perspectiva da teoria da agência e contingencial: um estudo com empresas listadas na BM\&FBovespa. In: CONGRESSO USP DE CONTROLADORIA E CONTABILIDADE, 15, 2015, São Paulo. Anais[...]. São Paulo: FEA-USP, 2015. Link. Acesso em: 25 jul. 2019.

MARTINS, E.; DINIZ, J. A.; MIRANDA, G. J. Análise didática das demonstrações contábeis. São Paulo: Atlas, 2014.

MCKILLOP, D.; WILSON, J. O. S. Credit Unions: a theoretical and empirical overview. Financial Markets, Institutions \& Instruments, [s.l.], v. 20, n. 3, p. 79-123, 2011.

MEINEN, Ê. PORT, M. Cooperativismo Financeiro: percurso histórico, perspectivas e desafios. Brasília: Confebras, 2014.

MEINEN, E. Cooperativismo Financeiro: virtudes e oportunidades. Brasília: Editora Confebras, 2016.

MOON, B-J. Antecedents and outcomes of strategic thinking. Journal of Business Research, [s.l], v. 66, n. 10, p. 1698-1708, 2013. Link. Acesso em: 25 jul. 2019.

MURRO, E. V. B.; TEIXEIRA, G. B.; BEUREN, I. M.; SCHERER, L. M.; LIMA, G. A. S. F. de. Relação entre folga organizacional e inovação em empresas da BM\&FBovespa. In: CONGRESSO USP DE CONTROLADORIA E CONTABILIDADE, 14, 2014, São Paulo. Anais[...]. São Paulo: FEA-USP, 2014. Link. Acesso em: 25 jul. 2019.

RIXON, D.; LIGHTSTONE, K. Impact of international financial reporting standards on canadian credit unions. International Journal of Business, Accounting, \& Finance. [s.I.], v. 10, n. 1, 2016.

SILVA, A. da; PADILHA, E. S.; SILVA, T. P. da. Análise da Performance Econômico-Financeira das 25 maiores cooperativas de crédito brasileiras. Desenvolvimento em Questão, [s.I.], v. 13, n. 32, out./dez. 2015.

TRINDADE, L. Z.; BIALOSKORSKI NETO, S. Análise e percepção dos custos das práticas de governança corporativa: um estudo de caso. Contextus - Revista Contemporânea de Economia e Gestão, Fortaleza, v. 12, n. 3, set/dez., 2014. Link. Acesso em: 25 jul. 2019.

WHITTINGTON, R.; CAILLUET, L.; YAKIS-DOUGLAS, B. Opening strategy: evolution of a precarious profession. British Journal of Management, [s.I.], v. 22, p. 531-544, 2011. Link. Acesso em: 25 jul. 2019.

WESTRUP, M. N.; CAMILO, S. P. O.; ESTEVAM, D. de O. Dominância de tomadores e poupadores nas cooperativas de crédito: análise sob a ótica da teoria da agência. In: SEMINÁRIOS EM ADMINISTRAÇÃO, 20, 2017, São Paulo. Anais[...]. São Paulo: FEA-USP, 2017.

WORLD COUNCIL OF CREDIT UNIONS. Why Credit Unions? 2019a. Link. Acesso em: 25 jul. 2019.

WORLD COUNCIL OF CREDIT UNIONS. Our Global Reach. 2019b. Link. Acesso em: 25 jul. 2019. 


\section{Contato:}

Ramon Rodrigues dos Santos

E-mail: ramonrdgs@gmail.com

Aldo Leonardo Cunha Callado

E-mail: aldocallado@yahoo.com.br

Joséte Florencio dos Santos

E-mail: jfs@ufpe.br 